\title{
Sociolinguistic determinants of heritage language maintenance and second language acquisition in bilingual immigrant speakers*
}

\begin{abstract}
The objective of the study was to scrutinise the determinants of heritage language maintenance and second language acquisition in immigrant speakers and assess their significance and weight. Over one hundred cases of bilingual speakers with Polish as L1 (heritage language; Polish speakers abroad) and as L2 (national language; immigrant learners of Polish in Poland) were investigated in order to better understand the linguistic changes and multilingual practices involved in the process of relocating to another country. The cases underwent quantitative and qualitative analysis. The results revealed that in most cases bilinguals are at a high risk of losing their L1, and L2 becomes their dominant language. With the dominance of $\mathrm{L} 2$, identification with the culture of the country of residence also increases in bilinguals. Formal instruction in L1 proves to be the most important factor in heritage language maintenance, and the preservation of a sense of identification with the heritage culture. An important role in L1 and also L2 development is played by parental support and their actions.
\end{abstract}

KEYWORDS: bilingualism, heritage language, language maintenance, second language acquisition, family language policy, multilingual practices, formal language learning, identity.

\section{INTRODUCTION}

The modern world is characterised by the rapid globalisation of the economy, and thus - unprecedented on such a large scale - an increase in human mobility. One of its expressions is that many people, often with their entire families,

* The results of this analysis were first presented at the Sociolinguistics Symposium, University of Auckland, New Zealand, 27-30.06.2018. 
move to another country for political, economic or ideological reasons. International mobility has resulted in a diversity of transnational and crosslinguistic families, families in which multilingualism is a dominant cultural feature (Lanza \& Wei 2016). Many of them are faced with serious and difficult decisions concerning family language policies as they integrate into a new community (King \& Fogle 2013).

Emigration is closely related to the issue of social and cultural integration. In public discourse, integration is often viewed from the perspective of the destination state of the emigration, with proficiency in the national language being viewed as the main indicator of integration. For example, in recent debates on school success and integration across the world, politicians have made demands in the media for transnational families with a minority and / or immigrant background to use the majority language at home, e.g. in New Zealand, where a report from the Office of Ethnic Affairs suggested that migrant families should consider speaking English to their children to improve their level of English (New Zealand's Office of Ethnic Affairs 2013, after King \& Cunningham 2016: 81). Where the language of the family (often referred to as an inherited or a heritage language - e.g. Cvikić, Novak Milić \& Aladrović Slovaček 2016; Bertelle 2018) does not have any prestige in the destination country, and it can even be seen as a factor hindering integration, the family is left with the choice of whether to turn their back on their heritage language or try to preserve it through various intentional and consistent actions.

Thus, when it comes to the rich spectrum of issues related to family language policies and educational topics affecting integration in a new community, for the purposes of this analysis we have chosen primarily those related to preserving or losing a family language. We also concentrate on issues connected with shaping bilingual competence, possible dominance of the second language over the heritage language, and shaping the identity of a bilingual person. In our study, we focus on bilingualism as a socio-cultural and educational resource, in the sense in which De Houwer (2015) refers to "harmonious bilingualism".

Based on the above, the objectives of this paper are to present the results of an analysis of over one hundred case studies in order to identify common factors and processes affecting bilingual practices and cultural integration of bilingual immigrant speakers, with a focus on people with Polish as their heritage language (L1) or their second language (L2). The aim of the analysis was to identify factors determining their heritage language maintenance or loss and their second language acquisition. 


\section{DEFINITION OF BILINGUALISM}

In this study, we will deal with individual bilingualism, leaving the issues of social and group bilingualism beyond the scope of our direct interest. From the entire spectrum of definitions of bilingualism, covering both extreme positions, represented, at one end, by Bloomfield (1933: 56), who required from a bilingual person "native-like control of two languages", and, at the other end by Hall (1952: 14, after Haugen 1987: 14), who admitted those who had "at least some knowledge and control of the grammatical structure of the second language" as bilingual persons, we chose a position in which a distinction is made between "surface competence" in the second language (Basic Interpersonal Communicative Skills / BICS) and "academically related language competence" (Cognitive Academic Language Proficiency / Academic Language Proficiency / CALP, Cummins 1979; cf. Baker 2011). Accordingly, a bilingual person is a person who has such a degree of proficiency in both of his or her languages that it allows him or her to perform complex cognitive operations, such as processing and expressing knowledge in both languages, regardless of whether they are developed to the same or comparable degree ("balanced bilingualism") or whether one of them is the person's dominant language and the other is a weaker language ("functional bilingualism", cf. Aleemi 1991: 72; Jonekeit \& Kielhöfer 2002: 12; Baker 2011: 12).

However, the criterion of language competence (criterion 1) is not the only determinant of bilingualism in this study. In light of the literature on the subject (e.g. Arsenian 1937/1972; Wei 2008; Baker 2011), we adopted further criteria to distinguish people with high language competence in two (or more) languages from those who are bilingual (multilingual). These further criteria are:

1) the age of onset of the process of acquiring a second language - we consider a bilingual person to be someone whose first close contact with both languages took place during the so-called sensitive period (cf. e.g. Patkowski 1980), that is to say during the first 10 years of their life, when the most intensive processes of first language acquisition occur and when a second language can be acquired by a child as "his or her mother tongue" (cf. Wode 2000, 2004) ${ }^{1}$;

2) an individual assessment of their own bilingualism - we consider a person to be bilingual if they are aware of their own bilingualism, irrespective of any objective evaluation of his or her language proficiency in both

\footnotetext{
${ }^{1}$ For a detailed discussion and review of the literature on the controversy of "critical age" and "sensitive period" in language acquisition, i.a. the "thresholds" for the development of particular language skills, see Olpińska-Szkiełko (2013: 56 ff).
} 
languages. In other words, a person who subjectively describes himself or herself as a bilingual individual (Aleemi 1991; Jonekeit \& Kielhöfer 2002);

3) the social and cultural context in which the bilingualism developed we consider a person to be bilingual if they acquired both languages in a natural bi- or multilingual environment. For the purposes of our analysis, this means in the specific situation of a family emigrating to a new country of residence.

In this paper, L1 is understood as the first language in terms of the chronology of acquisition, irrespective of whether it is the dominant language of the bilingual person or his or her weaker language. It is a language acquired in the family of a bilingual person, the language of his or her parents and their country of origin, also referred to in this paper as a heritage language or an inherited language.

Consequently, L2 is defined as the second language acquired by a bilingual person, even if it has become a dominant language. L2 is the national language of the new country of residence, acquired in the more extended social environment of a bilingual person, e.g. in kindergarten or at school.

\section{THE STUDY}

\subsection{The subject of analysis}

The analysis focused on case studies of bilingual speakers. These were conducted by students at the Faculty of Applied Linguistics of the University of Warsaw in the years 2013-2017 as part of a research project devoted to selected aspects of bilingualism² ${ }^{2}$ Each biography was prepared by a different student. All the student researchers participating in the project agreed for their case studies to be used in a further analysis. The interviewees' personal data were anonymised. For the purposes of this analysis, only biographies which received a positive evaluation and fulfilled a predefined set of criteria (see Section 2) were taken into consideration.

Language biographies of bilinguals (in some cases multilingual speakers) were prepared on the basis of interviews. To complete the task, the student researchers were assigned to conduct an unstructured interview, that is to say the interviews did not take place according to a predefined questionnaire to minimise the risk of suggesting certain responses. On the contrary, the researchers were free to choose and formulate questions. Generally speaking, the questions

${ }^{2}$ The case studies that were the subject of analysis in the present paper have not been published yet. The materials have been documented for the purpose of the project and are in the authors' possession. Other materials collected as part of this project were used for further analyses in Olpińska-Szkiełko (2016) and Banasiak and Olpińska-Szkiełko (2019). 
referred to the family situation of bilingual (sometimes multilingual) speakers, their attitudes to both of the languages and cultures, their own bilingualism (and biculturalism), as well as a subjective assessment of their linguistic competence in both languages and their experiences connected with bilingualism. In four cases, the bilinguals reported their own linguistic biography and analysed their own language development and skills.

In relation to the four criteria specified previously (see Section 2), 143 case studies were initially selected for analysis. However, since we wanted to identify those sociolinguistic determinants that are responsible for L1 / heritage language maintenance or loss and L2 acquisition in bilingual immigrant speakers, we had to concentrate on families who had spent a longer time in a new country of residence because the processes of integrating, identifying with the new community, as well as linguistic processes of loss or preservation of L1 and acquisition of L2, and it becoming the dominant language etc., need time. Thus, as a result of further analysis, the cases of families who often changed their country of residence or resided in a country for a short time due to work in a diplomatic corps or business (five cases), and also those cases of families whose stay in the L2 country was shorter than 5 years or whose return to the L1 country occurred before the child turned 10 (i.e. in the sensitive period; 14 cases) were excluded from further analysis. Next, we selected for further analysis only those cases in which L1 or L2 was Polish, and ruled out 11 cases in which the two languages described were not Polish. In total, 113 cases remained for the final analysis.

\subsection{Limitations of the study}

Although a case study analysis is "one of the most common forms of qualitative inquiry" (Duff 2012: 95), the presented study can also be considered to be quantitative due to the number of cases. Nonetheless, the authors of this paper are fully aware of the limitations of the study and the fact that it is difficult to generalise even from a larger number of case studies and extrapolate to a broader population. Our goal was, accordingly, not to universalise, but to particularise and to exemplify phenomena and certain common features and dependencies as described in the literature. In other words, we aimed at corroborating previous findings in a concrete and personal manner. We also chose not to employ an experimental design, e.g. proficiency tests to test the significance of findings statistically, because of the heterogeneity of the acquired material. Furthermore, although we chose for our analysis exclusively such cases which were described fairly and fully, and the results of the study are consistent with the literature on the subject, we approach the material with considerable caution. 


\subsection{Quantitative analysis}

The quantitative analysis of the 113 case studies, performed in terms of the parents' countries of origins and the family's country of residence, reflects the two distinct directions: emigration of Polish families and immigration to Poland. Out of the 113 cases, there were 89 cases of Polish families emigrating to other countries and 24 cases of families which came to live in Poland. Most Polish families emigrated to English-speaking countries such as: the USA (21), Great Britain (12), Canada (10), Ireland (4), Australia (1) and Kuwait (with English as L2 - 1 case) - a total of 49 cases. The second most popular choice for Polish families were German-speaking countries such as: Germany (17) and Austria (2) - in total 19 cases. Further in the ranking were French-speaking countries such as: France (7) and Belgium (2) - 9 in total, and then Italy and Norway (4 each), followed by Denmark, Finland, Spain and China (with Russian as L2) - with 1 case per country.

With regard to emigration to Poland, there were cases of families coming from Ukraine - 7 cases, and 1 further case where L1 was not the Ukrainian language but Russian ( 8 cases in total), from Russia -3 cases (one of them from contemporary Azerbaijan, former Soviet Union, L1 = Russian), Belarus - 2 cases with Russian as L1, Vietnam - 3 cases, Armenia - 3 cases, Mongolia - 2 cases, Chechnya -2 cases, and Serbia - 1 case.

\subsection{Qualitative analysis}

In all the analysed cases, L2 - as the national language of the destination country - was considered a relatively more prestigious language than L1. The relative social prestige of the two languages, L1 and L2, stems from the mutual relations between both social groups - the L2 social majority and the L1 social minority - primarily in the dominance of one group over the other and in the socioeconomic status and appropriate cultural background of both groups (cf. Ben-Zeev 1977: 33; Aleemi 1991: 164), as well as in the importance of the languages in the international arena (e.g. the high prestige of English as a modern lingua franca). These relationships are reflected in the media and education and have a strong impact on the attitudes of group members - including the bilinguals who were the subject of analysis, their families and their social environments towards both of the languages and cultures. In the analysed case studies, L2, with more relative social prestige than L1, was, according to the relevant literature (cf. Ben-Zeev 1977; Cummins 1982; Arnberg 1987; Skutnabb-Kangas 1987; Aleemi 1991 etc.), more prone to dominate L1. It can also be assumed in our study that 
the bilingual persons will identify more with the L2 culture than with the culture of the country of their parents' origin (L1 culture). This analysis should help to answer the question of whether this is really the case.

The qualitative analysis was performed in terms of:

1. Identification with L1 and L2 - understood as an emotional bond with the respective language and culture and a sense of belonging to the respective community;

2. Language competence in L1 and L2;

3. The role of L1 formal learning, especially development of reading and writing skills in L1 (despite education in L2);

4. Parental support in L1 and L2 development, e.g. the amount and quality of contact with L1 users, as well as the attitudes of the bilinguals' parents, relatives, and peers to their bilingualism.

All these aspects will be described in the following sections.

\subsubsection{Identification with L1 and L2 - language and culture}

The analysis confirmed that the issue of the identity of bilingual persons with a migrant background is extremely complex. Generally, it can be stated that the bilinguals in this study identified with the language and culture of the social majority (L2) in almost $100 \%$ of cases, as shown by Duc (case study (CS) by J. Mechlińska), who said: "I am Polish, I received Polish citizenship and I fully identify with Polish culture. My parents are Vietnamese, that is why I can speak Vietnamese and I know the culture of the country, but I do not recognise it as my own and sometimes I do not understand it $^{\prime \prime}$. However, it must be stressed that Duc, in making such a confession about his identity, could be viewed as an exception. In most cases, the bilingual individuals avoided making an open statement regarding whether they identified or not with both their heritage language / culture and their L2 together with the culture of their country of residence. In 13 cases, the bilinguals declared full identification with the L2 community and culture, as the community and culture they grew up in, e.g. Karolina (CS by M. Kamela), who said that she "owed much to France, and the person she now was 'had been shaped' there". Some bilinguals were conscious of the change in their identity that occurred when moving from identifying with the language and culture of their origin country towards identifying with the language and culture of the country of their current residence, like Gabriel (CS by A. Skowy-

${ }^{3}$ All translations of statements by bilingual persons in this study were made by the authors of this paper. 
ska), who repeated in his interview a couple of times: "when I was young I was Polish, now I am French".

Sometimes the identity formation process in bilingual people was associated with some painful and unpleasant experiences. Seweryn (CS by P.K. Pełszyk) reported that his peers in a Belgian school "laughed at him because of his [Polish] roots". Under the influence of this, he ceased to use his L1 completely during his teenage years, even when communicating with his sister. Only at university did he change his attitude towards the Polish language (and culture), but he still maintained that "being a Belgian is more prestigious than being a Pole". Interestingly, our analysis showed that unpleasant experiences related to the bilinguals' origin did not affect their sense of identification with the second language and culture (see 3.4.4.). The above-quoted Duc from Vietnam (immigrated to Poland at the age of 1) experienced, for instance, "several unpleasant racist situations" on the part of the children in his kindergarten. Despite these experiences, he fully identified with his L2 and the Polish community and culture. In several cases, a strong bond with the L2 country was maintained even after returning to the country of origin. This was the case with Kasia (CS by M. Grudzińska), who, after returning to the L1 country (Poland), declared that she wanted to return to the L2 country "as soon as possible". This sense of belonging to the L2 community could also in some cases be a source of unpleasant experiences, such as in the case of Karolina (CS by O. Kaliska), who faced alienation after returning to the L1 country (Poland) on the part of her peers who believed that "she considered herself better than them".

The above examples of Seweryn, Kasia and Karolina show an interesting point that our analysis revealed. They demonstrate that the sense of identification with the L2 country and L2 culture - as was shared, as mentioned above, by almost all of the bilingual respondents in our analysis - should often be deduced not on the basis of explicit declarations by a bilingual person, but from indirect premises contained in his or her statements. In spite of the absent declarations, bilingual persons' identification with the language and culture of their country of residence can nonetheless be distinctly inferred from their declared life plans regarding further education and career, a lack of willingness to change where they reside, e.g. return to the L1 country, etc.

Equally important, in no more than 12 out of 113 cases did the bilinguals state that they identified with their heritage language and culture (e.g. Daniel, CS by A. Jamróz; Samuel, CS by M. Marcjanik). In such cases, however, further analysis showed that those declarations should be treated with caution. Five out of those 12 bilinguals declared that they did not stay in "much" contact with their L1 country (in 4 cases - with Poland and in 1 case - with Ukraine) 
and did not plan to visit it. In one further of these 12 cases, the bilingual person (Armenak, CS by W. Malinowska) admitted that he "had little contact with the [Armenian] culture, as no one in his family had paid any attention to it". In another case, the bilingual person (Maria, CS by M. Sadowska) stated that only "a certain bond" connected her with her L1 country (Ukraine), and another bilingual person (Marion, CS by M. Onuczyńska) declared an attachment to Polish (L1) culture and language but at the same time she stated that she felt German (German was her L2). It seems that here it can also be inferred more from the premises concerning the bilingual persons' private life and career choices than from the (few) statements made by them regarding their attitudes towards their heritage language and culture. This time, however, our analysis showed that in most cases relations with the country of origin were much weaker than with the country of residence.

Our analysis also revealed that the connection with, or interest in, one's heritage language and culture in bilingual individuals - regardless of direct or indirect declarations of identification with it or regardless of the lack of such declarations - almost always showed itself indirectly, as e.g. in the case of Maria (CS by M. Grochowalska), who decided to study Polish philology (in Germany) as an additional subject (Nebenfach) despite her limited knowledge of the Polish language (her L1), or Solomija (CS by B. Kramar), who declared that she wanted to speak to her prospective children in Ukrainian - her L1 - in spite of not having much contact with Ukraine.

Significantly, a surprisingly low number of bilingual persons, as few as 3 out of 113 cases, declared equal and full identification with L1 and L2 as well as with both cultures without any doubt or reservations (although one of them Maciek, CS by J. Krupinska - later changed his attitude and stated that, after coming to live in Poland - his L1 country - as an adult, he realised that he had "never felt Canadian"). What is more, bilinguals also very rarely admitted that they felt no ties or that they did not identify with their languages and cultures. Only in 3 out of 113 cases did the bilinguals openly say that they did not identify with their heritage language and culture (in 1 case the bilingual person changed his attitude after coming to his L1 country, Poland, for a longer stay with his relatives - Mike, CS by K. Mazalewska). One of these people (Weronika, CS by J. Bernach) reported that she did not identify with any language and culture for a long time, but after many years she finally identified with her L2 (German). Accordingly, only four bilingual persons stated directly that they did not identify with their second language and culture. One of them, "a bilingual woman" (CS by A. Kucharska), referred, for instance, to her L2 country - Poland - as "only the country where her parents earn money". 


\subsubsection{Language competence in L1 and L2}

In almost all cases, the bilinguals reported their competence in L2 as equivalent to the competence of native speakers of the respective language and stated that their L1 was their weaker language. In a mere three cases did the bilingual subjects estimate their language competence as "not fully developed either in L1 or in L2". By contrast, only in one case - Maryna's (CS by A. Castillo Lozano), who went to university in both countries - can the L2 and L1 competence be viewed as fully developed and equal. Admittedly, in another three cases, the bilinguals also estimated their competence in L1 and L2 as being equal, but it seems that one should approach the self-assessment of language competence in these cases with an abundance of caution, given their reported limited contacts with L1 speakers outside the family, lack of L1 education and insufficient L1 experience in their professional lives. In six cases, the bilinguals subjectively estimated their L1 competence as being even higher than their L2 competence, but again, one should approach the self-assessment of language competence in at least three out of these six cases with caution. The other three cases were cases of people who returned (as teenagers or adults) to Poland and were living there.

Apart from those exceptional cases mentioned above, in the vast majority of bilingual immigrant speakers L2 is their dominant language. The dominance of L2 is reported by bilinguals even when they came to the L2 country relatively late (e.g. at the age of ten) and even though they received formal instruction in L1, were motivated to learn L1, were hard-working (both children and parents) and received support from their parents and other persons.

Language deficiencies in L1 were reported by bilinguals in 26 of the analysed cases. Siergiej (CS by S. Novikov), who attended a Russian school in Poland from Grade 1 to the "Matura" school-leaving exam, found shortcomings in his "specialist language" knowledge, i.e. terminology concerning the content of school subjects. In addition to specialised language, the bilingual persons (in addition to Siergiej, two others) felt clearly that they were deficient in reading and writing skills in L1, sometimes even despite the fact that they had returned to Poland (e.g. Agnes, CS by K. Brożyna). In 18 cases, the bilinguals reported that they had only developed oral skills in L1 but not literacy. Ngoc Anh (aka Ania, CS by Z. Gawrońska) said, for instance, that "she was able to read and write [in Vietnamese] at a child's level in primary school". Oksana (CS by I. Muravytska) said that she could read in Ukrainian but could not write, and Link (CS by A. Rybak) stated that she could only count in Vietnamese, but all other language processing took place in her L2 (Polish). In two cases, the 
bilingual subjects reported that they spoke L1 with an L2 accent: Ania (CS by J. Dobrzyńska) spoke Polish with a German accent and the above-mentioned Ngoc Anh / Ania spoke Vietnamese with a Polish accent. Moreover, the bilinguals often felt that "they could not find the right words" in L1. They often completed their sentences with words in L2 and sometimes also made grammatical errors. A. Smolak described in her case study the case of "her bilingual cousin", saying "I noticed during the conversation that all the sentences that my cousin formulated were similar in structure [...]. This made her statements in Polish rather monotonous, their structure sometimes unnatural and artificial [...] her utterances in this language are much poorer in terms of style". In another case, that of Viktoria (CS by S. Ciach), it was even reported that there was a frequent "mixing of languages" in adulthood.

\subsubsection{The role of formal instruction in $\mathrm{L} 1$}

The role of formal learning of L1, and studying in L1 (despite being educated in L2), especially the development of reading and writing skills in L1, proves to be the most important factor in maintaining L1 competence. Our qualitative analysis revealed that the issue of whether the bilingual people received formal instruction in $\mathrm{L} 1$ had more influence on the maintenance of their L1 than the age of immigration. In many cases, the bilingual subjects reported that they were taught literacy and received formal instruction in how to use L1. Many of them admitted that reading and writing in L1, as well as being taught L1 grammar and spelling - either at home (most often by their mothers, though sometimes by grandmothers or private tutors) or in the form of additional classes - resulted in a great improvement in their language skills. In three cases, the bilingual persons learnt to read in L1 on their own: Lejla (CS by A. Mijas) learnt to read Cyrillic at the age of 8-9; Anna (CS by A. Lantner-Rypień) used the famous Polish primer by K. Falski to develop reading skills in Polish; and Jan (CS by N. Hrechukha) acquired the same skill at the age of $15-16$.

Although they were aware of the importance that the development of reading and writing skills had for their heritage language, in many cases bilingual individuals felt it was a huge and unwanted burden and stated that they did not want to attend L1 classes. The most common reasons for this were:

- the classes took place at weekends or in the afternoon - "when other children were having fun, the bilinguals had to go to school" (Klaudia, CS by K. Topolewska); 
- a "double load", e.g. obligatory reading at the regular L2-school and obligatory reading in L1 (Samuel, CS by M. Marcjanik);

- a lot of work and strict, demanding teachers (Agata, CS by E. Rudnik);

- the lack of parental support (Wiktoria, CS by N. Zagórna);

- no sense of making headway in learning L1 (Kasia, CS by N. Truszkowska);

- the boring content to be learnt (Karolina, CS by J. Maleszewska).

\subsubsection{Parental support in L1 and L2 development}

There were some single cases among the analysed case studies in which parents did not support their children in acquiring the linguistic skills either in L1 or in L2 - like, for instance, the above-mentioned Jan (CS by N. Hrechukha), who learnt to read in his L1, Polish, himself. However, in most cases, parents actively supported L1 development in their children. The actions taken by the parents to support L1 development are listed below:

- using L1 at home, almost in all cases (a few exceptions will be discussed below);

- attending additional classes in L1 - reported in 26 cases, and in one case parents organised an L1 (Armenian) school by themselves (Arman, CS by V. Piskova);

- visiting L1 country during the holidays (to see grandparents, cousins etc.), from two weeks to two months - reported in 21 cases; in one case, a friendship with a female cousin significantly improved the bilingual person's L1 knowledge (Dawid, CS by K. Koziara);

- watching TV (e.g. cartoons, films) in L1 - reported in 13 cases; in three cases - additionally, listening to the radio or music;

- visiting L1 speaking relatives for a longer period of time (e.g. grandparents, cousins) - reported in ten cases;

- reading books in L1 - reported in seven cases; in two cases - additionally, reading newspapers and magazines;

- communicating via the Internet (e.g. Skype) - reported in six cases;

- teaching the children to read and write in L1 at home - reported in six cases;

- going to church (five cases - Catholic, one case - Orthodox) or taking Catholic religion classes - reported in six cases;

- contacting L1 speaking relatives, friends and acquaintances in the L2 country - reported in four cases;

- taking part in summer camps or summer play groups (half a day) in the L1 country - reported in three cases; 
- cultivating L1 cultural traditions, e.g. celebrating festivals (in one case always coming to the L1 country - Poland - to celebrate Christmas and Easter) - reported in three cases;

- hiring a private L1 tutor - reported in two cases;

- hiring an L1-speaking nanny at home - reported in two cases;

- making use of an Internet school ("Libratus") for Polish children abroad reported in one case, and

- playing board games - reported in one case.

In most cases, the family language was L1 (sometimes because parents did not know L2), but in almost all cases (with only three exceptions - see below), L2 was also present in the daily life of the family in one form or another. Very often the parents did not pay attention to which language the children answered them in when they were addressed in L1. In most cases, the parents also accepted the children using L2 in communication between siblings.

The ways in which families dealt with their language policies and bilingual practices were very diverse. At one end of the scale, in three of the cases analysed, the parents did not accept the use of L2 at home (in all three cases, the parents' behaviour did not prevent L2 domination in the children):

- in Duc's case (CS by J. Mechlińska), his parents forbade him to use L2 at home after they realised that his competence in Vietnamese was much weaker than in Polish;

- in Ngoc Anh / Ania's case (CS by Z. Gawrońska), her father accepted the use of Polish, or even used it himself, while her mother "shouted at the father on those occasions";

- in Agata's case (CS by J. Adamowicz), her Polish parents in Canada did not answer the children (siblings) when they addressed them in English instead of Polish.

At the other end of the scale, in a few cases (e.g. Alisa, CS by A. Pogodina; Ania, CS by J. Dobrzyńska), the parents decided to use only L2 at home in response to "communication problems in the kindergarten" and, in one case, they did not want "to bother their child" with L1 (Claudia, CS by E. Fokt). In a few additional cases - interestingly in the cases of families who emigrated to German speaking countries - the parents were initially inclined to abandon L1 as the family language, but regretted it and tried to overcome that situation later, i.e. by refusing to use L2 at home (e.g. Claudia, CS by E. Fokt; Pawel, CS by N. Szymańska; Wojciech and Natalia, CS by K. Rzepka). Such behaviours resulted in considerable emotional problems in the children and had significant consequences in their later life. One such consequence is presumably the fact that Wojciech, who married a Pole and came to live in Poland, did not want to bring up his children bilingually - in Polish and German - although the latter was his dominant language. 
In 14 cases, the parents used varying proportions of L1 and L2 in communication at home, but it did not seem to be a purposeful and consistent attempt because, as the bilinguals themselves judged in their own reports, this happened either "without a clear schedule" (Maciek, CS by M. Onuczyczyńska), only "depending on the situation" (Olivier and Sara, CS by W. Tokaj), or "on occasions" (e.g. Mike, CS by K. Mazalewska). Sometimes "[the parents] tried to speak Polish at home" (Martin and Nicole, CS by K. Lipka, underlining by the authors) or they spoke L1 at home as a rule, but "they sometimes abandoned that rule" (Karolina, CS by A. Czerwińska-Trzaskowska).

In some additional cases, the parents deliberately supported the development of L2 in their children by:

- hiring an L2-speaking nanny (six cases, e.g. Adam, CS by M. Siwek - he had an English-speaking nanny);

- introducing the teaching of L2 at home - in five cases by the mother (two English, two German, one French, e.g. Gabriel, CS by A. Skowyska), in four cases - by both parents (one Finnish - Krzyś, CS by J. Krueger, one Italian - Ela, CS by N. Dąbrowska, one German - Adam, CS by J. Popławska and one English - Klaudia, CS by K. Topolewicz), and in one case by the father (Eva, CS by M. Skwirosz).

All of the parents' multilingual policies and practices listed and discussed above reflected their attitudes towards their children' bilingualism and towards both their languages and cultures. The parents also directly influenced the attitudes of their bilingual offspring themselves. Both positive and possibly negative attitudes of the bilinguals also resulted from experiences they gained in the surrounding environment, especially among their peers. As many as 13 bilingual individuals reported experiencing feelings of alienation, isolation, humiliation, desperation as well as others' negative feelings towards them or even open discrimination (at least this many admitted this openly in the analysed case studies). Two more bilingual subjects, Olivier (CS by W. Tokaj) in Germany and Mikołaj (CS by A. Gozdur) in Norway, reported that they had not experienced direct animosity but they felt bad when their parents talked to them in their L1 (Polish) in the presence of friends. On the other hand, in a mere seven cases the bilinguals clearly indicated that they did not feel they were the subject of prejudice or isolated in any way. In just one case, "a bilingual woman" from Serbia (CS by A. Kucharska) stated that she "felt liked and received support and help" in a Polish school. Another bilingual person, Olek (CS by M. Wilczyńska), who left Poland to live in Norway, emphasised in his interview that the Norwegians treat other cultures with enormous respect and interest. Karolina (CS by A. Czerwińska-Trzaskoma) had a similar impression in relation to Canadians. 


\subsection{Conclusions}

The analysis showed that the declarations of bilingual people regarding their identification with their L1 and L2, as well as with the cultures of the L1 and L2 countries, did not coincide with the conclusions that could be drawn by analysing their language biographies and their life situations. The analysis showed that bilingual people much less frequently declare identification with the language and culture of their (new) country of residence (the country of their second language - L2) than could be justified based on their life choices as well as private and professional life plans e.g. their choices regarding education (university degrees), professional career, place of residence and possibly changing it, etc. The bilinguals more often declared that they identified with the language and culture of their country of origin (or their parents' origin) - the country of their inherited language - L1 - than could be inferred from their declared life plans. In most cases (with hardly any exceptions), the bilinguals admitted that their language competence in L2 was higher than in L1 (L2 is their dominant language, and L1 their weaker language), and (with a few exceptions) they did not express a desire to move from the L2 country to the L1 country. In many cases, they did not even show any special interest in visiting or having any contact with the L1 country. Despite this, they emphasised how they identified with the culture of the L1 country in several cases. The bilingual people rated their L1 competence higher than an assessment of their language activity (e.g. how often and in which situations they actually use L1) would indicate. It seems that they were inclined to overestimate their language skills as if attempting to adapt to the expectations that, in their opinion, could be put to them as speakers of the inherited language by other L1 speakers. In fact, the language competences of the bilingual people in L1 were very diverse, and their level of L1 proficiency largely depended on the actions they and their families took to support the development of their weaker language. The development of reading and writing competences in many cases especially enhanced their L1 competence.

When it comes to a subjective assessment of their own bilingual competence, the vast majority of the bilinguals exhibited a positive attitude towards their bilingualism. The analysis showed that adults especially appreciated the benefits of bilingualism, although earlier, in childhood, their assessments had varied in many cases they obviously felt the burden of having a "double portion" of learning - regular schooling for L2, and in L2, and additional schooling for L1, and in L1, often on Saturdays, Sundays or in the afternoons. In a few cases, the bilinguals also recalled situations where they felt discriminated against, based on their origin and their belonging to more than one language and culture. Positive and negative experiences of bilingualism were often reflected in the pursuit, or 
abandonment, of raising their own children bilingually. Many bilingual people emphasised that they wished their children to be raised bilingually, but among the case studies analysed there were also those where bilingual people consciously gave up bringing their offspring up in a bilingual fashion.

With regard to the role of formally learning L1, or learning in L1, based on our qualitative analysis, it appeared to be the dominating factor in maintaining L1 competence in bilingual speakers. The findings showed that even the age of immigration had less of an impact on L1 maintenance than receiving L1 formal instruction, especially in terms of reading and writing skills.

Finally, it has to be stated that all the parents of bilingual speakers from our study played an active role in their children's language development. Most parents actively participated in their children's L1 development in a variety of ways, and some of them also supported the development of their children's L2 competence.

\section{REFERENCES}

Aleemi, J. (1991). Zur sozialen und psychischen Situation von Bilingualen. Frankfurt a. M.: Peter Lang Verlag.

Arnberg, L. (1987). Raising children bilingually: The pre-school years. Clevedon: Multilingual Matters. Arsenian, S. (1937/1972). Bilingualism and mental development: A study of bilingual children in New York City. New York: College Press.

Baker, C. (2011). Foundations of bilingual education and bilingualism [5 ${ }^{\text {th }}$ ed.]. Bristol: Multilingual Matters.

Banasiak, I. / Olpińska-Szkiełko, M. (2019). Language use of a bilingual child - an analysis of case studies. Kwartalnik Neofilologiczny, 3, 479-491. DOI: 10.24425/kn.2019.129909.

Ben-Zeev, S. (1977). Mechanism by which childhood bilingualism affects understanding of language and cognitive structures. In: P.A. Hornby (ed.), Bilingualism. Psychological, social and educational implications (pp. 29-51). New York: Academic Press.

Bertelle, L. (2018). Wptyw wybranych czynników emocjonalnych i społecznych na wychowanie dziecka dwujezycznego w rodzinie mieszanej. Ph.D thesis defended at the University of Warsaw (WLS UW).

Bloomfield, L. (1933). Language. New York: Holt.

Cummins, J. (1979). Cognitive academic language proficiency, linguistic interdependence, the optimum age question and some other matters. Working Papers on Bilingualism, 19, 121-129.

Cummins, J. (1982). Die Schwellenniveau- und die Interdependenz-Hypothese: Erklärungen zum Erfolg zweisprachiger Erziehung. In: J. Swift (ed.), Bilinguale und Multikulturelle Erziehung (pp. 34-43). Würzburg: Königshausen + Neumann.

Cvikić, L. / Novak Milić, J. / Aladrović Slovaček, K. (2016). The role of formal language instruction in maintenance of heritage language: The case of the Croatian language. In: S. Grucza / M. Olpińska-Szkiełko / P. Romanowski (eds.), Advances in understanding multilingualism: A global perspective (pp. 12-23). Warszawa: Peter Lang Edition.

De Houwer, A. (2015). Harmonious bilingual development: Young families' well-being in language contact situations. International Journal of Bilingualism, 19 (2), 169-184. 
Duff, P.A. (2012). How to carry out case study research. In: A. Mackey / S.M. Gass (eds.), Research methods in SLA. A practical guide (pp. 95-114). Malden, MA: Blackwell Wiley.

Hall, R.A. (1952). Bilingualism and applied linguistics. Zeitschrift für Phonetik und allgemeinde Sprachwissenschft, 6, 13-30.

Haugen, E. (1987). Blessings of Babel: Bilingualism and language planning. Berlin: Mouton de Gruyter. Jonekeit, S. / Kielhöfer, B. (2002). Zweisprachige Kindererziehung $\left[11^{\text {th }}\right.$ ed.]. Tübingen: Stauffenburg. King, J. / Cunningham, U. (2016). Intergenerational transmission of minority languages in New Zealand: Methodological issues. In: S. Grucza / M. Olpińska-Szkiełko / P. Romanowski (eds.), Advances in understanding multilingualism: A global perspective (pp. 81-104). Warszawa: Peter Lang Edition.

King, K. / Fogle, L. (2013). Family language policy and bilingual parenting. Language Teaching, $46(2), 172-194$.

Lanza, E. / Wei, L. (2016). Multilingual encounters in transcultural families. Journal of Multilingual and Multicultural Development, 37 (7), 653-654. DOI: 10.1080/01434632.2016.1151198.

Olpińska-Szkiełko, M. (2013). Wychowanie dwujęzyczne w przedszkolu [2nd ed.]. Warszawa: Studia Naukowe IKSI UW. http://sn.iksi.uw.edu.pl/tomy/.

Olpińska-Szkiełko, M. (2016). Individuality vs. regularity of bilingualism - Conclusions from a case study analysis. In: S. Grucza / M. Olpińska-Szkiełko / P. Romanowski (eds.), Bilingual landscape of the contemporary world (pp. 159-172). Warszawa: Peter Lang Edition.

Patkowski, M.S. (1980). The sensitive period for the acquisition of syntax in a second language. Language Learning, 30, 449-472.

Skutnabb-Kangas, T. (1987). Bilingualism or not: The education of minorities. Clevedon: Multilingual Matters Ltd.

Wei, L. (2008). Research perspectives on bilingualism and multilingualism. In: L. Wei / M.G. Moyer (eds.), The Blackwell guide to research methods in bilingualism and multilingualism (pp. 1-17). Malden / Oxford / Carlton: Blackwell Publishing.

Wode, H. (2000). Mehrsprachigkeit durch bilinguale Kindergärten. Kiel: Englisches Seminar und Zentrum für Mehrsprachigkeit und Sprachkontakt der Universität Kiel, Sokrates Comenius.

Wode, H. (2004). Frühes (Fremd) Sprachen lernen. Englisch ab Kita und Grundschule: Warum? Wie? Was bringt es? Kiel: Verein für frühe Mehrsprachigkeit an Kindertageseinrichtungen und Schulen FMKS e.V.

Received: 25.05.2020; revised: 12.10 .2020

ILONA BANASIAK

Uniwersytet Warszawski

ie.banasiak@uw.edu.pl

ORCID: 0000-0002-3096-2839

MAGDALENA OLPIŃSKA-SZKIEŁKO

Uniwersytet Warszawski

m.olpinska@uw.edu.pl

ORCID: 0000-0002-2996-3885 
